\title{
Adherens Junction: Molecular Architecture and Regulation
}

\author{
Wenxiang Meng and Masatoshi Takeichi \\ RIKEN Center for Developmental Biology, Chuo-ku, Kobe 650-0047, Japan \\ Correspondence: takeichi@cdb.riken.jp
}

The adherens junction $(\mathrm{AJ})$ is an element of the cell-cell junction in which cadherin receptors bridge the neighboring plasma membranes via their homophilic interactions. Cadherins associate with cytoplasmic proteins, called catenins, which in turn bind to cytoskeletal components, such as actin filaments and microtubules. These molecular complexes further interact with other proteins, including signaling molecules, rendering the AJs into highly dynamic and regulatable structures. The AJs of such nature contribute to the physical linking of cells, as well as to the regulation of cell-cell contacts, which is essential for morphogenesis and remodeling of tissues and organs. Thus, elucidating the molecular architecture of the AJs and their regulatory mechanisms are crucial for understanding how the multicellular system is organized.

$T^{\text {hed }}$ he adherens junction (AJ) is a form of cell-cell adhesion structure observed in a variety of cell types, as well as in different animal species. It is characterized by a pair of plasma membranes apposed with a distance of $10-20 \mathrm{~nm}$ between them, whose intercellular space is occupied by rod-shaped molecules bridging the membranes (Hirokawa and Heuser 1981; Miyaguchi 2000), and the cytoplasmic side of the $\mathrm{AJ}$ is associated with condensed actin filaments. In polarized epithelia of vertebrates, the $\mathrm{AJ}$ is part of the tripartite junctional complex localized at the juxtaluminal region, which comprises the tight junction (zonula occludens), AJ, and desmosome (macula adherens) aligned in this order from the apical end of the junction (Farquhar and Palade 1963). In this type of epithelia, the AJ is specifically termed the "zonula adherens" or "adhesion belt," as it completely encloses the cells along with the F-actin lining, called the circumferential actin belt (Fig. 1). The AJs in other cell types assume different morphologies: For example, the AJs in fibroblastic cells are spotty and discontinuous (Yonemura et al. 1995), and those in neurons are organized into tiny puncta as a constituent of the synaptic junctions (Uchida et al. 1996).

A major function of AJs is to maintain the physical association between cells, as disruption of them causes loosening of cell-cell contacts, leading to disorganization of tissue architecture. Calcium chelators such as EDTA and EGTA are widely used as a reagent to promote the dissociation of cells in tissues or monolayer cultures. A major target of these chelators is the

Editors: W. James Nelson and Elaine Fuchs

Additional Perspectives on Cell Junctions available at www.cshperspectives.org

Copyright (C) 2009 Cold Spring Harbor Laboratory Press; all rights reserved; doi: 10.1101/cshperspect.a002899

Cite this article as Cold Spring Harb Perspect Biol 2009;1:a002899 
W. Meng and M. Takeichi
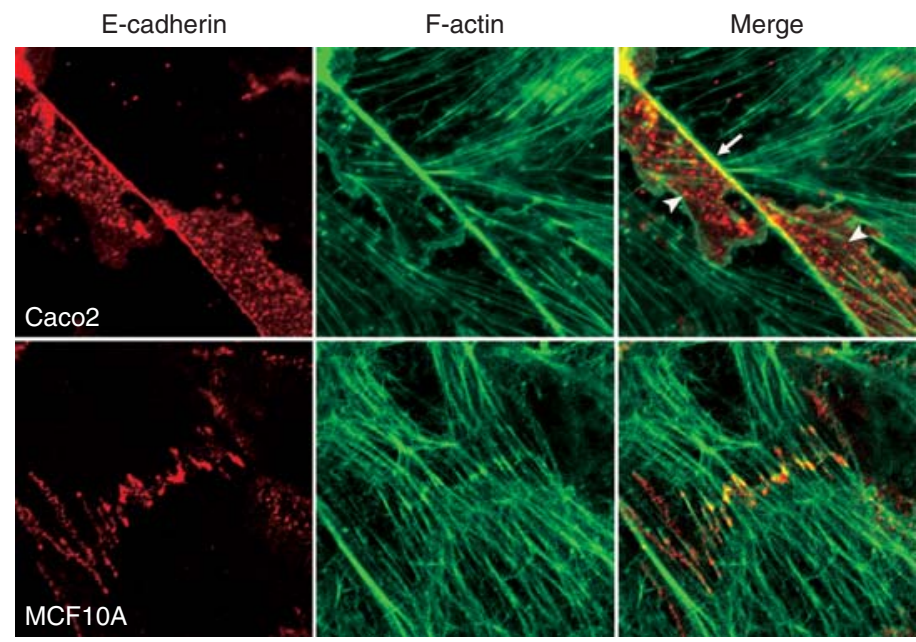

Figure 1. Morphological variations of the adherens junction. In Caco2 cells (colonic carcinoma line), E-cadherin is localized along the actin circumferential belt to organize the zonula adherens (arrow). At the lateral portions of cell junction (arrowheads), E-cadherin signals are punctate, only occasionally overlapping with actin signals in this specific sample. The lateral patterns of cadherin and actin distribution, however, vary with cellular conditions. In MCF10A cells (mammary epithelial line), spotty adherens junctions are seen, where actin filaments perpendicularly terminate at E-cadherin puncta.

$\mathrm{AJ}$, as this is a calcium-sensitive structure; although, calcium removal is generally insufficient for the complete dispersion of cells because of the presence of calcium-independent cell-cell adhesion mechanisms (Takeichi et al. 1977). Early studies to search for the molecules responsible for the calcium-dependent junctions resulted in the identification of a group of type-I transmembrane proteins, and its founding member was termed cadherin (Yoshida and Takeichi 1982; Yoshida-Noro et al. 1984). Related molecules identified were also called by various names, such as uvomorulin (Peyrieras et al. 1983), LCAM (Gallin et al. 1983), and ACAM (Volk and Geiger 1984). Later studies revealed that the cadherins form a superfamily, and therefore, the original cadherins are now called "classic" cadherins.

Another series of studies have identified nectins, a family of immunoglobulin-like transmembrane proteins, as an $\mathrm{AJ}$ component. Nectins function in a calcium-independent way to promote cell-cell adhesion (Nakanishi and Takai 2004). In this article, we overview the molecular organization of the AJs constructed with these membrane proteins, as well as the regulatory mechanisms that operate to sustain or remodel these junctions, paying much attention to the linkages between the AJ and cytoskeletal or signaling proteins.

\section{CADHERINS}

The classic cadherin family comprises approximately 20 members that share a common domain organization. The members are called E-cadherin (cdh1), N-cadherin (cdh2), and so on, each of which shows a distinct tissue distribution pattern (Takeichi 1988). Their extracellular domain is divided into five repetitive subdomains, called cadherin repeats or EC domains, and each subdomain contains calcium-binding sequences (Overduin et al. 1995). The interaction of calcium ions with these sequences controls the conformation of the extracellular domain (Pokutta et al. 1994), switching its adhesive function "off" and "on." On its association with calcium, the extracellular domain of cadherins on a cell undergoes homophilic interaction with that of cadherins present on the apposed cells (Fig. 2). The precise mechanism for this homophilic interaction is still controversial (Troyanovsky 2005), although current studies support the 


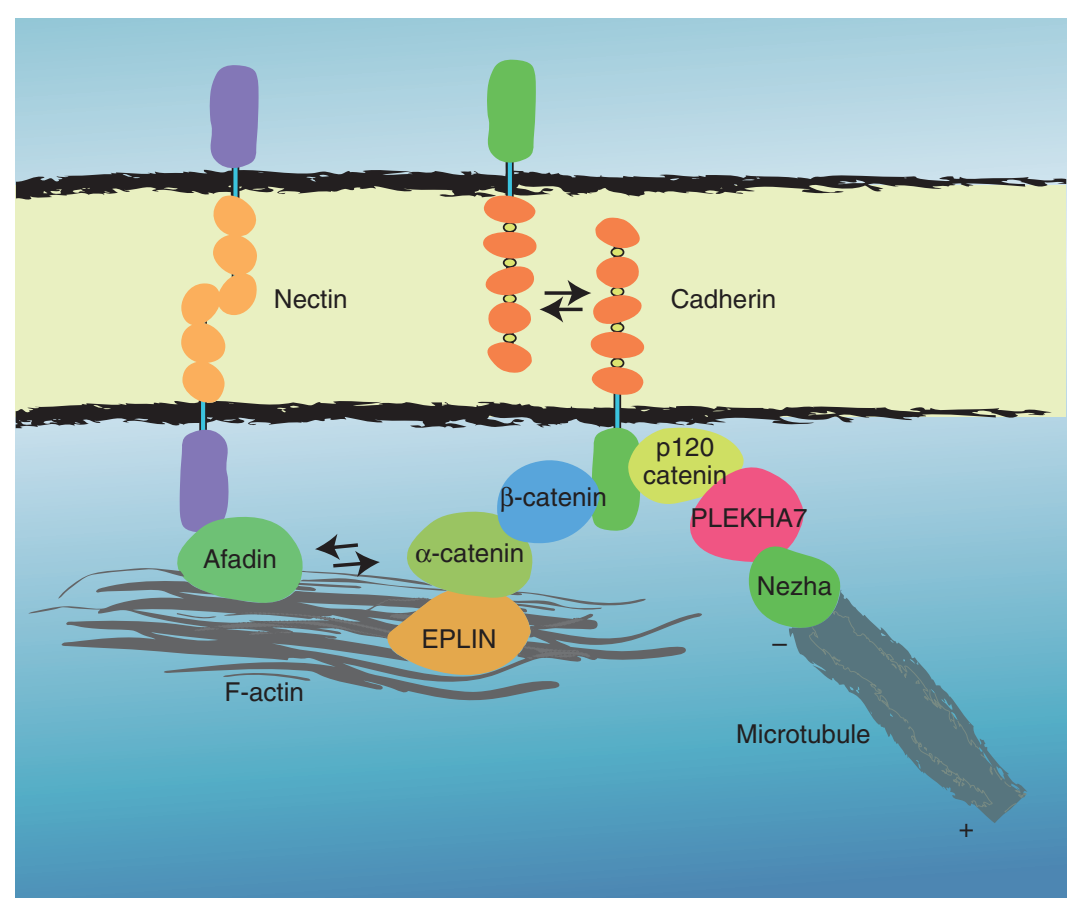

Figure 2. Representative molecular constituents of the zonula adherens. These constituents vary with the types of adherens junction.

idea that a trans binding between cadherin monomers via their EC1 domains initiates their interactions (Zhang et al. 2009).

The calcium-sensitive sequences are highly conserved among the family members, whose sequences are the hallmarks for this family, and all classic cadherins show a similar calcium dependence. Other sequences in the extracellular domain, however, vary, and this sequence variation confers the adhesive specificity on each member (Nose et al. 1988). For example, E-cadherin preferentially binds E-cadherin, and $\mathrm{N}$-cadherin does so to $\mathrm{N}$-cadherin; although, the degree of the selectivity changes depending on the partners (Shimoyama et al. 2000; Patel et al. 2006). This nature of classic cadherins has been implicated in the sorting of different cell types (Takeichi 1988).

AJs occur in a wide variety of animal species, and classic cadherin-type molecules have been identified in many species (Oda et al. 2005). However, their molecular organization is not perfectly conserved. For example, although Drosophila E-cadherin (DE-cadherin) is a component of the AJ, it has seven EC domains, instead of the five in the vertebrate classic cadherins (Oda et al. 1994). The other Drosophila classic cadherin, DN-cadherin, has even 17 EC domains (Iwai et al. 1997). These Drosophila cadherins also contain other domains, such as EGF-like and laminin globular-like domains, inserted between the set of EC domains and the transmembrane domain. As a result, these Drosophila cadherins are much larger in size than the vertebrate ones, despite the similar appearance of their AJs. The functional importance of AJs also differs among species. For example, Caenorhabditis elegans has a classic-cadherin-type molecule (HMR-1), but its role in cell junction formation is limited: HMR-1-deficient animals fail to enclose the epidermal sheets, but their general cell junctions look normal even in the absence of this cadherin (Cox et al. 2004). The organization of apical junctional complexes is also different between vertebrates and invertebrates. In Drosophila, the relative positions of the AJ and tight junction are inverse; that is, the $\mathrm{AJ}$ is 
located above the septate junction, which is considered as a structure equivalent to the vertebrate tight junction. Irrespective of these species-dependent diversifications, the key structure and function of the cadherin cytoplasmic domain is highly conserved among different species; that is, the classic cadherins from any species interact with their conserved cytoplasmic partners (see the following).

After the discovery of the classic cadherins, a number of other molecules that share the conserved EC domains but have divergent cytoplasmic sequences were identified, and these are collectively called nonclassic cadherins. These include desmosomal cadherins (Wheeler et al. 1991; Buxton and Magee 1992), protocadherins (Redies et al. 2005; Morishita and Yagi 2007), Fat and Dachsous cadherins (Saburi and McNeill 2005; Tanoue and Takeichi 2005), and Flamingo/Celsr (Takeichi 2007) (see McNeill et al. 2009). Among them, desmosomal cadherins are the closest to the classic cadherins, and desmosomes, in fact, are similar in appearance to AJs, though not identical from a number of aspects (Holthofer et al. 2007) (see Green et al. 2009; Delva et al. 2009). Except for the desmosomal cadherins, other nonclassic cadherins appear not to organize specialized junctions, nor to be the components essential for AJ formation; although, they generally can undergo homophilic interactions at the cellcell interfaces. These nonclassic cadherins seem to have acquired unique molecular roles, rather than that for the physical linking of cells. For example, some of the protocadherins negatively regulate the classic cadherin-dependent adhesion (Chen and Gumbiner 2006), and Fat (Nollet et al. 2000; Strutt and Strutt 2005; Tanoue and Takeichi 2005) and Flamingo (Usui et al. 1999) regulate planar cellular polarity as well as other forms of cellular interactions.

\section{CADHERIN-CATENIN COMPLEX}

The cytoplasmic domains are highly conserved among the classic cadherin members, and they bind common cytoplasmic molecules, collectively called catenins (Fig. 2). The juxtamembrane portion of the cytoplasmic domain associates with p120-catenin, which belongs to a subfamily of the armadillo proteins (Reynolds et al. 1992; Shibamoto et al. 1995; Hatzfeld 2005). The carboxy-terminal half of the cytoplasmic domain, on the other hand, binds $\beta$-catenin or plakoglobin ( $\gamma$-catenin), which are close relatives of each other (Ozawa et al. 1989; Knudsen and Wheelock 1992; Ozawa and Kemler 1992). As mentioned above, these molecular partners for the cytoplasmic domain are well conserved among different animal species; e.g., its invertebrate versions can bind both p120-catenin (JAC-1 in C. elegans) and $\beta$-catenin (Armadillo in Drosophila; HMP-2 in C. elegans) (Peifer and Wieschaus 1990; Cox et al. 2004). These catenins in turn associate with a variety of other molecules, including cytoskeletal proteins and their regulators. These cytoplasmic components of AJ affect the adhesive action of the extracellular domain of cadherins in various ways, leading to alterations in the strength and stability of cell-cell contacts.

\section{INTERACTIONS WITH THE ACTIN CYTOSKELETON}

The AJ is morphologically associated with actin filaments, posing the questions of how this association is established and what role the actin plays in $\mathrm{AJ}$ organization and function. A key player is thought to be $\alpha$-catenin, a molecule similar to vinculin (Herrenknecht et al. 1991; Nagafuchi et al. 1991). The $\alpha$-catenin binds $\beta$-catenin, resulting in the formation of the cadherin- $\beta$-catenin- $\alpha$-catenin complex. Early biochemical studies showed that $\alpha$-catenin can interact with actin filaments (Rimm et al. 1995), giving rise to the general belief that $\alpha$-catenin acts as a linker between the cadherin- $\beta$-catenin complex and F-actin. However, this concept was challenged by the finding that the $\alpha$-catenin complexed with cadherin and $\beta$-catenin cannot bind F-actin in vitro and that only free $\alpha$-catenins can do so (Drees et al. 2005; Yamada et al. 2005). This finding suggested the possibility that the cadherin- $\beta$-catenin- $\alpha$-catenin complex might interact with F-actin via some other 
mediator(s). In fact, $\alpha$-catenin has been shown to associate with actin-binding proteins such as formin (Kobielak et al. 2004) and vinculin (Watabe-Uchida et al. 1998), and a very recent study identified another actin-binding protein, EPLIN (epithelial protein lost in neoplasm; also known as Lima-1), as an $\alpha$-catenin partner (Abe and Takeichi 2008). EPLIN is known to enhance the bundling of actin filaments and to stabilize them by suppressing F-actin depolymerization (Maul et al. 2003). The EPLIN can bind $\alpha$-catenin when the latter is associated with the cadherin- $\beta$-catenin complex, and this entire complex binds F-actin. This finding illustrates a novel pathway for the interaction between cadherin and F-actin (Fig. 2).

It should be noted that the morphology of actin-AJ association differs with the cell types or cellular conditions (Yonemura et al. 1995). Although actin filaments run parallel along the ZA in simple cuboidal or columnar epithelia, these filaments often perpendicularly terminate at cell-cell borders in many other junctions, e.g., in those of stratified epitheliumderived cells and fibroblastic cells, and also in immature junctions of most cell types (Fig. 1). It is highly possible that different molecular mechanisms operate for the linking of F-actin to AJs in such different types of junction. In fact, even in the absence of EPLIN, F-actin still morphologically associates with AJs (see the following). Meanwhile, the actin-associated cadherins do not necessarily form a static domain. In some cell lines, actin filaments are aligned from the basal to apical end of cell junctions, and these actins display a type of retrograde flow. Cadherins are tethered to these actin filaments in an $\alpha$-catenin-dependent manner and move together with the actins, displaying "cadherin flow" (Kametani and Takeichi 2007); although, the biological role of this flow is not understood yet. In mature epithelia, $\alpha$-catenin is also important for regulating the mobility of cadherins (Cavey et al. 2008) (see Stepniak et al. 2009).

What happens if the linkage between the cadherin-catenin complex and F-actin is disrupted? When $\alpha$-catenin is removed, AJ organization is disrupted, and the apical actin belt becomes segregated from the cadherincatenin complex (Watabe-Uchida et al. 1998). If this occurs in neural epithelia in vivo, their architecture is seriously damaged (Vasioukhin et al. 2001). Removal of neural $\alpha$-catenin $(\alpha \mathrm{N}$-catenin $)$ from synaptic AJs destabilizes synaptic contacts (Abe et al. 2004). On the other hand, EPLIN loss in epithelia results in different types of defects at the junctions. The circumferential actin belt disappears, being converted to radially oriented actin filaments, indicating that EPLIN is important not only for the linkage between cadherin and F-actin but also for stabilizing this unique configuration of actin fibers (Abe and Takeichi 2008). Importantly, the actin filaments, rearranged as a result of EPLIN loss, still target cadherins, which now assume a spotty localization as seen in fibroblasts or immature epithelial junctions. This finding suggests that EPLIN is not the sole linker between cadherin and F-actin and that other linkers must be present and also suggests the possibility that the shape of AJs could be altered by the type of cadherinactin linkers.

Because the actin filaments are essential for AJ assembly, regulators of these filaments would be expected to affect it. In fact, Rho-family small GTPases, such as RhoA, Rac1, and Cdc42, as well as their GEFs and GAPs, have been shown to regulate $\mathrm{AJ}$ formation and integrity (Braga 2000). Because these molecules are used for a wide variety of cell behavior, precise dissection of whether a given GTPase targets the actin filaments directly involved in junction formation or those involved in other processes, such as cell motility, is important for our correct understanding of the roles of these enzymes. aPKC has also been shown to be essential for the circumferential actin belt formation in epithelial cells. When aPKC is inactivated, the circumferential actin belt is lost, and AJs become spot-like (Suzuki et al. 2002). In vivo, aPKC knockout results in the loss of adherens junctions in neuroepithelial cells (Imai et al. 2006). It has been proposed that the action of aPKC is to antagonize the myosin-II-driven centripetal contraction of the circumferential actin cables (Kishikawa et al. 2008). 
The contractility of AJ-associated circumferential actin belts is used for morphogenesis. A well-known example is the Shroom3dependent constriction of the zonula adherens (ZA) in epithelial layers, where constriction plays an important role in epithelial folding or bending (Haigo et al. 2003; Hildebrand 2005). In this case, the actin-binding protein Shroom3 recruits Rho kinases (ROCKs) near the $\mathrm{ZA}$, and activates myosin-II, inducing the contraction of the circumferential actin belts (Nishimura and Takeichi 2008). The actomyosin-dependent regulation of the $\mathrm{AJ}$ is also implicated in cell intercalation during early morphogenesis of Drosophila embryos (Bertet et al. 2004; Zallen and Wieschaus 2004; Blankenship et al. 2006).

\section{INTERACTIONS WITH MICROTUBULES}

As compared with the actin cytoskeleton, less attention has been paid to microtubules (MTs) with reference to the structure and function of the AJ. Actually, the MTs do not show specialized condensation at the AJ, contrasted with the unique bundling of actin fibers along the AJ. However, MTs have occasionally been observed to be located in a close proximity to the AJ, running parallel to this junction. Moreover, the radially extending MTs are targeted to the AJs with their plus ends in a CLIP-170-dependent manner, and blocking of the MT extension toward the AJs causes a reduction in the accumulation of junctional E-cadherin (Stehbens et al. 2006). In addition, dynein was found to bind $\beta$-catenin, and this $\beta$-catenin-associated dynein was proposed to tether MTs to cell junctions (Ligon et al. 2001; Shaw et al. 2007). These observations suggest a potential interaction of AJ with MT plus ends, and their interaction seems to have some roles in $\mathrm{AJ}$ assembly. In support of this idea, reagents that depolymerize MTs are known to disrupt the integrity of the AJs (Waterman-Storer et al. 2000), and even inhibit the disassembly of cell junctions (Ivanov et al. 2006)

Recent studies have also revealed that MT minus ends interact with AJs via p120-catenin (p120). This catenin recognizes and binds a specific sequence located in the juxtamembrane region of the cadherin cytoplasmic domain. The p120-cadherin binding is known to play a central role in the stability of cadherin-mediated junctions; i.e., when p120 is removed, the plasma membrane-associated cadherins become endocytosed, leading to reduced cell-cell associations (see the following discussion). This action of p120 requires the armadillo domain occupying its central region (Liu et al. 2007). Other series of studies have found that p120 can associate with MTs (Chen et al. 2003; Roczniak-Ferguson and Reynolds 2003; Franz and Ridley 2004; Yanagisawa et al. 2004), and this ability of p120 requires its carboxy-terminal domain (Ichii and Takeichi 2007), suggesting that the amino-terminal and armadillo domains of this catenin have separate functions. Further studies on the amino-terminal domain identified a new partner for p120 (Meng et al. 2008). This is PLEKHA7, which binds the amino-terminal domain of p120. Intriguingly, this protein localizes specifically along the ZA, but not in other portions of the junctions in epithelial sheets, despite the ubiquitous distribution of p120 and cadherins at the cell-cell contacts. Depletion of PLEKHA7 exclusively disrupts the ZA, but not the entire cell-cell junctions, suggesting that this protein is specifically required to maintain the $\mathrm{ZA}$. Subsequently, PLEKHA7 was found to bind another protein, termed Nezha, which is again distributed along the ZA; although Nezha was also detected as punctate signals in the cytoplasm. Nezha displays an important property: It binds the minus ends of MTs, and tethers them to the ZA, allowing their extension and retraction from the cell junctions.

These studies have uncovered the presence of a novel population of MTs, whose minus ends are anchored at the $\mathrm{ZA}$ via the PLEKHA7-Nezha complex (Fig. 2). The functions of these MTs are not fully understood yet, but preliminary observations suggest that minus-end directed kinesin motors, such as KIFC3, use these MTs to transport themselves to the ZA. Depletion of PLEKHA7, Nezha, KIFC3, and MTs results in similar defects in ZA organization. Thus, these molecules 
appear to work together by forming a complex to sustain the ZA architecture. It should be re-emphasized that this novel molecular complex appears to be important only for the $\mathrm{ZA}$, but not for the entire cadherin-mediated cell-cell contacts, confirming that the ZA is a specialized domain of the cadherin-mediated junctions/AJs. The mechanisms of how PLEKHA7 interacts with p120 only at the ZA remains unknown.

In sum, evidence is accumulating that MTs play roles in AJ assembly, where both the plus and minus ends of MTs have been suggested to be involved. Although the molecular mechanisms for the plus-end interactions with AJs have not been determined yet, the two populations of MTs with the opposite polarity might cooperate together for AJ regulation.

\section{COOPERATION BETWEEN CADHERIN AND NECTIN}

Nectins are a family of immunoglobulinlike molecules, consisting of four members (Nakanishi and Takai 2004). They are accumulated at the AJ, colocalizing with cadherins (Fig. 2). The cytoplasmic domain of nectins associates with AF6/afadin via the carboxyterminal PDZ-binding motif of the former. Afadin, on the other hand, was shown to interact with $\alpha$-catenin, suggesting that a physical association might occur between the cadherin-catenin and nectin-afadin complexes (Tachibana et al. 2000). Because afadin is an actin-binding protein (Mandai et al. 1997; Takahashi et al. 1999), this system may also play a role in the linking of AJ to actin filaments.

Nectins interact with other nectins in either a homophilic or heterophilic way. Different from the classic cadherins, nectins prefer heterotypic partners to homotypic ones, and their heterophilic binding produces stronger cell-cell adhesion than the homophilic interactions (Fabre et al. 2002; Yasumi et al. 2003; Martinez-Rico et al. 2005). Importantly, during the process of early cell-cell contacts, nectins first accumulate at the contacts, and then cadherins follow them (Takai et al. 2003), suggesting that the former may guide the latter in their junctional localization. This can be seen in the following example: When cells expressing nectin-1 and nectin-3 are mixed, these nectins preferentially accumulate at the heterotypic interfaces of the cells. In these cells, cadherins also become predominantly concentrated at the heterotypic nectin-positive cell boundaries (Togashi et al. 2006). Thus, this form of nectin interaction serves for recruiting cadherins to heterotypic cell-cell borders, which are otherwise distributed throughout cell-cell borders. This ability of nectins is used for recruiting cadherins to the synaptic contacts formed between two distinct domains of hippocampal neurons, i.e., axons and dendrites, which express nectin-1 and nectin-3, respectively (Togashi et al. 2006). Thus, nectins show important cooperativity with classic cadherins in generating heterotypic cell-cell contacts.

\section{INTERACTIONS WITH CELL POLARITY REGULATORS}

How is the apical junctional complex located apically? The apico-basal polarity of cells is regulated by a couple of molecular complexes, including the aPKC-Par6-Par3 complex localized at a subapical region of the cell junction (Margolis and Borg 2005). Genetic analysis using Drosophila embryos showed that the Drosophila homolog of Par3 (Bazooka) could establish apical complexes in the absence of AJs, indicating that Bazooka acts upstream of AJ formation (Harris and Peifer 2005). Some reports, on the other hand, suggest the AJs have a physical interaction with these polarity factors: Par3 and Par6, but not aPKC, coprecipitate with VE-cadherin, the endothelial-specific cadherin (Iden et al. 2006). Par3/Bazooka colocalizes with cadherins in epithelial junctions (Harris and Peifer 2005; Afonso and Henrique 2006). These observations illustrate a possible pathway by which the apical membrane domain is primarily determined by those apical determinants, and, in turn, the $\mathrm{AJ} / \mathrm{ZA}$ is recruited to this domain, possibly via interactions with the pre-existing Par complex. Cadherins may also interact with another polarity regulator, 
the Scrib-Dlg-Lgl complex localized at the lateral membrane (Reuver and Garner 1998; Navarro et al. 2005). However, the mechanisms responsible for the clustering of the three junctions, i.e., tight junction, $\mathrm{AJ}$, and desmosomes, to form the apical junctional complex and their alignment in a specific order remain unresolved.

\section{CADHERIN EXPRESSION AND RECYCLING}

The $\mathrm{AJ}$ in mature tissues appears to be a static structure, but actually, cadherin molecules are turning over, and their surface levels are controlled by various mechanisms. Elucidating these mechanisms is important for a molecular understanding of the homeostatic nature of cell junctions. In epithelial cells, the newly synthesized cadherins are transferred from the Golgi to AJs via an exocyst-dependent mechanism (Yeaman et al. 2004). For recycling, E-cadherin is transported to recycling endosomes, and then trafficked to late endosomes for return to the cell surface. DE-cadherin trafficking depends on the interaction of Rab11 and $\beta$-catenin with exocyst components Sec15 and Sec10, respectively (Langevin et al. 2005).

The cell surface-located cadherins are stabilized by their homophilic interactions. When cell-cell junctions are artificially disrupted by depletion of extracellular calcium or by other means, the cadherins are actively internalized (Kartenbeck et al. 1991). Under the physiological situation, p120 plays a critical role in cadherin stability (Reynolds 2007). It has been proposed that the attachment of p120 to cadherin masks a dileucine motif on the juxtamembrane region of the cytoplasmic domain, which is sensitive to endocytotic signals (Miyashita and Ozawa 2007), and thereby stabilizes the cadherins. The p120-cadherin binding is strengthened by the interaction of p120 with nectin-associated afadin in a way depending on Rap1, a small GTPase known to be important for AJ formation (Kooistra et al. 2007), and this results in the suppression of E-cadherin endocytosis (Hoshino et al. 2005). A component of the tight junction, PALS1, can also regulate the cadherin trafficking: In PALS1-knocked-down epithelial cells, the exocyst complex is mislocalized, and E-cadherin puncta accumulate in the cell periphery (Wang et al. 2007). Recently, the Cdc42-Par6-aPKC pathway was reported to stabilize the AJ via the control of Arp2/ 3-dependent endocytosis (Georgiou et al. 2008; Leibfried et al. 2008). Thus, the cadherin stability is regulated in a variety of ways.

The level of cadherins on the cell surface is also controlled by transcriptional and posttranscriptional regulators. Many zinc finger family transcription factors have been implicated in the control of cadherin expression. For example, the zinc finger transcription factor "Snail" is considered as a repressor of E-cadherin transcription, and the expression of Snail inversely correlates with that of E-cadherin (Cano et al. 2000). Other zincfinger-family transcription factors, such as SIP1, $\delta E F 1$, Slug, Twist, and E12, similarly act as cadherin transcription repressors through their interaction with the E-box (Remacle et al. 1999; Comijn et al. 2001; Perez-Moreno et al. 2001; Hajra et al. 2002; Yang et al. 2004). Recently, a family of micro RNAs (miRNAs), such as miR-200, was reported to control the expression level of E-cadherin during the epithelial-mesenchymal transition (EMT). Ectopic expression of miR-200 in cell lines upregulates the expression of E-cadherin. These microRNAs act on E-cadherin transcriptional

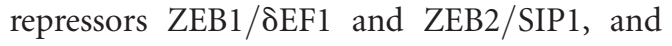
thereby regulate EMT (Gregory et al. 2008; Park et al. 2008). Another miRNA, miR-373, was found to induce E-cadherin expression by recognizing a target site in the promoter of the gene for E-cadherin (Li et al. 2006; Place et al. 2008). These findings provide novel insights into the regulation of cadherin gene expression, which shows highly complex patterns during development (Takeichi 1988).

\section{CONCLUDING REMARKS}

The AJs do not display highly specialized ultrastructures, except for having the actin undercoats, as compared with the tight junction, desmosome, and gap junction, each of which 
shows uniquely decorated plasma membranes or intercellular architecture. The relatively simple structure of the AJ may reflect its dynamic nature and flexibility. In fact, the overall morphology of AJs varies with the cell type and changes during morphogenetic cell rearrangements such as convergent-extension and EMT. The observations of AJ remodeling during Drosophila germ band extension suggest that the AJs function not only as a physical ligand between cells but also as an active regulator for cell rearrangement (Lecuit and Lenne 2007). Under these circumstances, studies on AJs will continue for answering at least two lines of questions: How are the AJs maintained or disrupted? And, how does the regulation of AJs contribute to normal morphogenetic cell behavior as well as to the pathogenic one, such as cancer invasion and metastasis?

The integrity of AJs is sustained by cytoplasmic components, including catenins and associated molecules, actin filaments, and microtubules, as well as by the recycling machinery. Although the entire system is apparently complicated, one of the crucial mechanisms to maintain the AJs obviously underlies the interplay of cadherin and the cytoskeleton. We have not obtained a complete answer to the long-standing question of how actin regulates the adhesive function of cadherins. Now, a new question has been posed: What role do MTs have in AJ assembly? Future studies are needed to resolve these problems, through the analysis of the roles of actin regulators and MT-associated proteins.

To understand the morphogenetic roles of AJs, physical and mathematical modeling is becoming a powerful tool (Honda et al. 2008). For example, anisotropy of cortical tension at the AJs has been shown to be sufficient to drive tissue elongation (Rauzi et al. 2008). On the experimental biology side, it will be important to delineate the cooperative mechanisms between AJs and other morphogenetic regulators that work at cell-cell borders, for example, planar cell polarity (PCP) signaling (Fanto and McNeill 2004), as AJs alone would not be sufficient for responding to so many morphogenetic signals.
Other important issues yet unanswered include how the morphology of AJs differs between cell types, and the roles of different classic cadherin members in AJ formation. Each cadherin subtype, which shows a unique tissue distribution, might confer some kind of tissue specificity on the structure and functions of AJs, but this concept has not been tested. The roles of nonclassic cadherins in $\mathrm{AJ}$ regulation is another interesting issue, as some protocadherins can down-regulate the functions of classic cadherins (Chen and Gumbiner 2006; Nakao et al. 2008). There must be a number of unknown interactions between the classic and nonclassic cadherin systems, as both of their components accumulate at cell-cell contacts. All these studies targeted on the AJ give us deeper insights into the problem of how individual cells, which can freely move when isolated, can regulate themselves via cell-cell contacts to generate highly ordered multicellular systems.

\section{ACKNOWLEDGMENTS}

We thank Katsutoshi Taguchi for photographs. Work in our laboratory was supported by the program Grants-in-Aid for Specially Promoted Research of the Ministry of Education, Science, Sports, and Culture of Japan.

\section{REFERENCES}

Abe K, Chisaka O, Van Roy F, Takeichi M. 2004. Stability of dendritic spines and synaptic contacts is controlled by $\alpha$ N-catenin. Nat Neurosci 7: 357-363.

Abe K, Takeichi M. 2008. EPLIN mediates linkage of the cadherin catenin complex to F-actin and stabilizes the circumferential actin belt. Proc Natl Acad Sci 105: 13-19.

Afonso C, Henrique D. 2006. PAR3 acts as a molecular organizer to define the apical domain of chick neuroepithelial cells. J Cell Sci 119: 4293-4304.

Bertet C, Sulak L, Lecuit T. 2004. Myosin-dependent junction remodelling controls planar cell intercalation and axis elongation. Nature 429: 667-671.

Blankenship JT, Backovic ST, Sanny JS, Weitz O, Zallen JA. 2006. Multicellular rosette formation links planar cell polarity to tissue morphogenesis. Dev Cell 11: 459-470.

Braga V. 2000. Epithelial cell shape: Cadherins and small GTPases. Exp Cell Res 261: 83-90. 
W. Meng and M. Takeichi

Buxton RS, Magee AI. 1992. Structure and interactions of desmosomal and other cadherins. Semin Cell Biol 3: $157-167$.

Cano A, Perez-Moreno MA, Rodrigo I, Locascio A, Blanco MJ, del Barrio MG, Portillo F, Nieto MA. 2000. The transcription factor snail controls epithelial-mesenchymal transitions by repressing E-cadherin expression. Nat Cell Biol 2: 76-83.

Cavey M, Rauzi M, Lenne PF, Lecuit T. 2008. A two-tiered mechanism for stabilization and immobilization of E-cadherin. Nature 453: 751-756.

Chen X, Gumbiner BM. 2006. Paraxial protocadherin mediates cell sorting and tissue morphogenesis by regulating C-cadherin adhesion activity. J Cell Biol 174: 301-313.

Chen X, Kojima S, Borisy GG, Green KJ. 2003. p120 catenin associates with kinesin and facilitates the transport of cadherin-catenin complexes to intercellular junctions. J Cell Biol 163: 547-557.

Comijn J, Berx G, Vermassen P, Verschueren K, van Grunsven L, Bruyneel E, Mareel M, Huylebroeck D, van Roy F. 2001. The two-handed E box binding zinc finger protein SIP1 downregulates E-cadherin and induces invasion. Mol Cell 7: 1267-1278.

Cox EA, Tuskey C, Hardin J. 2004. Cell adhesion receptors in C. elegans. J Cell Sci 117: 1867-1870.

Delva E, Tucker DK, Kowalczyk AP. 2009. The Desmosome. Cold Spring Harb Perspect Biol 1: a002543.

Drees F, Pokutta S, Yamada S, Nelson WJ, Weis WI. 2005. $\alpha$-Catenin is a molecular switch that binds E-cadherin- $\beta$-catenin and regulates actin-filament assembly. Cell 123: 903-915.

Fabre S, Reymond N, Cocchi F, Menotti L, Dubreuil P, Campadelli-Fiume G, Lopez M. 2002. Prominent role of the Ig-like $\mathrm{V}$ domain in trans-interactions of nectins. Nectin 3 and nectin 4 bind to the predicted $C-C^{\prime}-C^{\prime \prime}-D$ $\beta$-strands of the nectinl $\mathrm{V}$ domain. J Biol Chem 277: 27006-27013.

Fanto M, McNeill H. 2004. Planar polarity from flies to vertebrates. J Cell Sci 117: 527-533.

Farquhar MG, Palade GE. 1963. Junctional complexes in various epithelia. J Cell Biol 17: 375-412.

Franz CM, Ridley AJ. 2004. p120 catenin associates with microtubules: Inverse relationship between microtubule binding and Rho GTPase regulation. J Biol Chem 279: 6588-6594.

Gallin WJ, Edelman GM, Cunningham BA. 1983. Characterization of L-CAM, a major cell adhesion molecule from embryonic liver cells. Proc Natl Acad Sci 80: $1038-1042$.

Georgiou M, Marinari E, Burden J, Baum B. 2008. Cdc42, Par6, and aPKC regulate Arp2/3-mediated endocytosis to control local adherens junction stability. Curr Biol 18: $1631-1638$.

Green KJ, Getsios S, Troyanovsky S, Godsel LM. 2009. Intercellular junction assembly, dynamics and homeostasis. Cold Spring Harb Perspect Biol 2: a000125.

Gregory PA, Bracken CP, Bert AG, Goodall GJ. 2008. MicroRNAs as regulators of epithelial-mesenchymal transition. Cell Cycle 7: 3112-3118.

Haigo SL, Hildebrand JD, Harland RM, Wallingford JB. 2003. Shroom induces apical constriction and is required for hingepoint formation during neural tube closure. Curr Biol 13: 2125-2137.

Hajra KM, Chen DY, Fearon ER. 2002. The SLUG zinc-finger protein represses E-cadherin in breast cancer. Cancer Res 62: 1613-1618.

Harris TJ, Peifer M. 2005. The positioning and segregation of apical cues during epithelial polarity establishment in Drosophila. J Cell Biol 170: 813-823.

Hatzfeld M. 2005. The p120 family of cell adhesion molecules. Eur J Cell Biol 84: 205-214.

Herrenknecht K, Ozawa M, Eckerskorn C, Lottspeich F, Lenter M, Kemler R. 1991. The uvomorulin-anchorage protein $\alpha$ catenin is a vinculin homologue. Proc Natl Acad Sci 88: 9156-9160.

Hildebrand JD. 2005. Shroom regulates epithelial cell shape via the apical positioning of an actomyosin network. J Cell Sci 118: 5191-5203.

Hirokawa N, Heuser JE. 1981. Quick-freeze, deep-etch visualization of the cytoskeleton beneath surface differentiations of intestinal epithelial cells. J Cell Biol 91: 399-409.

Holthofer B, Windoffer R, Troyanovsky S, Leube RE. 2007. Structure and function of desmosomes. Int Rev Cytol 264: $65-163$.

Honda H, Nagai T, Tanemura M. 2008. Two different mechanisms of planar cell intercalation leading to tissue elongation. Dev Dyn 237: 1826-1836.

Hoshino T, Sakisaka T, Baba T, Yamada T, Kimura T, Takai Y. 2005. Regulation of E-cadherin endocytosis by nectin through afadin, Rap1, and p120ctn. J Biol Chem 280: 24095-24103.

Ichii T, Takeichi M. 2007. p120-catenin regulates microtubule dynamics and cell migration in a cadherinindependent manner. Genes Cells 12: 827-839.

Iden S, Rehder D, August B, Suzuki A, Wolburg-Buchholz K, Wolburg H, Ohno S, Behrens J, Vestweber D, Ebnet K. 2006. A distinct PAR complex associates physically with VE-cadherin in vertebrate endothelial cells. EMBO Rep 7: $1239-1246$

Imai F, Hirai S, Akimoto K, Koyama H, Miyata T, Ogawa M, Noguchi S, Sasaoka T, Noda T, Ohno S. 2006. Inactivation of aPKC $\lambda$ results in the loss of adherens junctions in neuroepithelial cells without affecting neurogenesis in mouse neocortex. Development 133: 1735-1744.

Ivanov AI, McCall IC, Babbin B, Samarin SN, Nusrat A, Parkos CA. 2006. Microtubules regulate disassembly of epithelial apical junctions. BMC Cell Biol 7: 12.

Iwai Y, Usui T, Hirano S, Steward R, Takeichi M, Uemura T. 1997. Axon patterning requires DN-cadherin, a novel neuronal adhesion receptor, in the Drosophila embryonic CNS. Neuron 19: 77-89.

Kametani Y, Takeichi M. 2007. Basal-to-apical cadherin flow at cell junctions. Nat Cell Biol 9: 92-98.

Kartenbeck J, Schmelz M, Franke WW, Geiger B. 1991. Endocytosis of junctional cadherins in bovine kidney epithelial (MDBK) cells cultured in low $\mathrm{Ca} 2+$ ion medium. J Cell Biol 113: 881-892.

Kishikawa M, Suzuki A, Ohno S. 2008. aPKC enables development of zonula adherens by antagonizing centripetal contraction of the circumferential actomyosin cables. J Cell Sci 121: 2481-2492. 
Knudsen KA, Wheelock MJ. 1992. Plakoglobin, or an 83-kD homologue distinct from $\beta$-catenin, interacts with E-cadherin and N-cadherin. J Cell Biol 118: 671-679.

Kobielak A, Pasolli HA, Fuchs E. 2004. Mammalian formin-1 participates in adherens junctions and polymerization of linear actin cables. Nat Cell Biol 6: 21-30.

Kooistra MR, Dube N, Bos JL. 2007. Rap1: A key regulator in cell-cell junction formation. J Cell Sci 120: 17-22.

Langevin J, Morgan MJ, Sibarita JB, Aresta S, Murthy M, Schwarz T, Camonis J, Bellaiche Y. 2005. Drosophila exocyst components Sec5, Sec6, and Sec15 regulate DE-Cadherin trafficking from recycling endosomes to the plasma membrane. Dev Cell 9: 365-376.

Lecuit T, Lenne PF. 2007. Cell surface mechanics and the control of cell shape, tissue patterns and morphogenesis. Nat Rev Mol Cell Biol 8: 633-644.

Leibfried A, Fricke R, Morgan MJ, Bogdan S, Bellaiche Y 2008. Drosophila Cip4 and WASp define a branch of the Cdc42-Par6-aPKC pathway regulating E-cadherin endocytosis. Curr Biol 18: 1639-1648.

Li LC, Okino ST, Zhao H, Pookot D, Place RF, Urakami S, Enokida H, Dahiya R. 2006. Small dsRNAs induce transcriptional activation in human cells. Proc Natl Acad Sci 103: 17337-17342.

Ligon LA, Karki S, Tokito M, Holzbaur EL. 2001. Dynein binds to beta-catenin and may tether microtubules at adherens junctions. Nat Cell Biol 3: 913-917.

Liu H, Komiya S, Shimizu M, Fukunaga Y, Nagafuchi A. 2007. Involvement of p120 carboxy-terminal domain in cadherin trafficking. Cell Struct Funct 32: 127-137.

Mandai K, Nakanishi H, Satoh A, Obaishi H, Wada M, Nishioka H, Itoh M, Mizoguchi A, Aoki T, Fujimoto T, Matsuda Y, Tsukita S, Takai Y. 1997. Afadin: A novel actin filament-binding protein with one PDZ domain localized at cadherin-based cell-to-cell adherens junction. J Cell Biol 139: 517-528.

Margolis B, Borg JP. 2005. Apicobasal polarity complexes. J Cell Sci 118: 5157-5159.

Martinez-Rico C, Pincet F, Perez E, Thiery JP, Shimizu K, Takai Y, Dufour S. 2005. Separation force measurements reveal different types of modulation of E-cadherinbased adhesion by nectin-1 and -3. J Biol Chem 280: $4753-4760$.

Maul RS, Song Y, Amann KJ, Gerbin SC, Pollard TD, Chang DD. 2003. EPLIN regulates actin dynamics by cross-linking and stabilizing filaments. J Cell Biol 160: 399-407.

McNeill H. 2009. Planar cell polarity: Keeping hairs straight is not so simple. Cold Spring Harb Perspect Biol 2: a003376.

Meng W, Mushika Y, Ichii T, Takeichi M. 2008. Anchorage of microtubule minus ends to adherens junctions regulates epithelial cell-cell contacts. Cell 135: 948-959.

Miyaguchi K. 2000. Ultrastructure of the zonula adherens revealed by rapid-freeze deep-etching. J Struct Biol 132: $169-178$.

Miyashita Y, Ozawa M. 2007. A dileucine motif in its cytoplasmic domain directs $\beta$-catenin-uncoupled E-cadherin to the lysosome. J Cell Sci 120: 4395-4406.
Morishita H, Yagi T. 2007. Protocadherin family: Diversity, structure, and function. Curr Opin Cell Biol 19: 584-592.

Nagafuchi A, Takeichi M, Tsukita S. 1991. The $102 \mathrm{kd}$ cadherin-associated protein: Similarity to vinculin and posttranscriptional regulation of expression. Cell 65: 849-857.

Nakanishi H, Takai Y. 2004. Roles of nectins in cell adhesion, migration and polarization. Biol Chem 385: 885-892.

Nakao S, Platek A, Hirano S, Takeichi M. 2008. Contact-dependent promotion of cell migration by the OL-protocadherin-Nap1 interaction. J Cell Biol 182: 395-410.

Navarro C, Nola S, Audebert S, Santoni MJ, Arsanto JP, Ginestier C, Marchetto S, Jacquemier J, Isnardon D, Le Bivic A, Birnbaum D, Borg JP. 2005. Junctional recruitment of mammalian Scribble relies on E-cadherin engagement. Oncogene 24: 4330-4339.

Nishimura T, Takeichi M. 2008. Shroom3-mediated recruitment of Rho kinases to the apical cell junctions regulates epithelial and neuroepithelial planar remodeling. Development 135: 1493-1502.

Nollet F, Kools P, van Roy F. 2000. Phylogenetic analysis of the cadherin superfamily allows identification of six major subfamilies besides several solitary members. J Mol Biol 299: 551-572.

Nose A, Nagafuchi A, Takeichi M. 1988. Expressed recombinant cadherins mediate cell sorting in model systems. Cell 54: $993-1001$.

Oda H, Uemura T, Harada Y, Iwai Y, Takeichi M. 1994. A Drosophila homolog of cadherin associated with armadillo and essential for embryonic cell-cell adhesion. Dev Biol 165: 716-726.

Oda H, Tagawa K, Akiyama-Oda Y. 2005. Diversification of epithelial adherens junctions with independent reductive changes in cadherin form: Identification of potential molecular synapomorphies among bilaterians. Evol Dev 7: 376-389.

Overduin M, Harvey TS, Bagby S, Tong KI, Yau P, Takeichi M, Ikura M. 1995. Solution structure of the epithelial cadherin domain responsible for selective cell adhesion. Science 267: 386-389.

Ozawa M, Kemler R. 1992. Molecular organization of the uvomorulin-catenin complex. J Cell Biol 116: 989-996.

Ozawa M, Baribault H, Kemler R. 1989. The cytoplasmic domain of the cell adhesion molecule uvomorulin associates with three independent proteins structurally related in different species. EMBO J 8: 1711-1717.

Park SM, Gaur AB, Lengyel E, Peter ME. 2008. The miR-200 family determines the epithelial phenotype of cancer cells by targeting the E-cadherin repressors ZEB1 and ZEB2. Genes Dev 22: 894-907.

Patel SD, Ciatto C, Chen CP, Bahna F, Rajebhosale M, Arkus N, Schieren I, Jessell TM, Honig B, Price SR, Shapiro L. 2006. Type II cadherin ectodomain structures: Implications for classical cadherin specificity. Cell 124: $1255-1268$.

Peifer M, Wieschaus E. 1990. The segment polarity gene armadillo encodes a functionally modular protein that is the Drosophila homolog of human plakoglobin. Cell 63: 1167-1176. 
W. Meng and M. Takeichi

Perez-Moreno MA, Locascio A, Rodrigo I, Dhondt G, Portillo F, Nieto MA, Cano A. 2001. A new role for E12/E47 in the repression of E-cadherin expression and epithelial-mesenchymal transitions. J Biol Chem 276: 27424-27431.

Peyrieras N, Hyafil F, Louvard D, Ploegh HL, Jacob F. 1983. Uvomorulin: A nonintegral membrane protein of early mouse embryo. Proc Natl Acad Sci 80: 6274-6277.

Place RF, Li LC, Pookot D, Noonan EJ, Dahiya R. 2008. MicroRNA-373 induces expression of genes with complementary promoter sequences. Proc Natl Acad Sci 105: $1608-1613$.

Pokutta S, Herrenknecht K, Kemler R, Engel J. 1994. Conformational changes of the recombinant extracellular domain of E-cadherin upon calcium binding. Eur J Biochem 223: 1019-1026.

Rauzi M, Verant P, Lecuit T, Lenne PF. 2008. Nature and anisotropy of cortical forces orienting Drosophila tissue morphogenesis. Nat Cell Biol 10: 1401-1410.

Redies C, Vanhalst K, Roy F. 2005. ס-Protocadherins: Unique structures and functions. Cell Mol Life Sci 62: 2840-2852.

Remacle JE, Kraft H, Lerchner W, Wuytens G, Collart C, Verschueren K, Smith JC, Huylebroeck D. 1999. New mode of DNA binding of multi-zinc finger transcription factors: $\delta E F 1$ family members bind with two hands to two target sites. EMBO J 18: 5073-5084.

Reuver SM, Garner CC. 1998. E-cadherin mediated cell adhesion recruits SAP97 into the cortical cytoskeleton. J Cell Sci 111: 1071-1080.

Reynolds AB. 2007. p120-catenin: Past and present. Biochim Biophys Acta 1773: 2-7.

Reynolds AB, Herbert L, Cleveland JL, Berg ST, Gaut JR. 1992. p120, a novel substrate of protein tyrosine kinase receptors and of p60v-src, is related to cadherin-binding factors beta-catenin, plakoglobin and armadillo. Oncogene 7: 2439-2445.

Rimm DL, Koslov ER, Kebriaei P, Cianci CD, Morrow JS. 1995. $\alpha 1(\mathrm{E})$-catenin is an actin-binding and -bundling protein mediating the attachment of F-actin to the membrane adhesion complex. Proc Natl Acad Sci 92: 8813-8817.

Roczniak-Ferguson A, Reynolds AB. 2003. Regulation of p120-catenin nucleocytoplasmic shuttling activity. J Cell Sci 116: 4201-4212.

Saburi S, McNeill H. 2005. Organising cells into tissues: New roles for cell adhesion molecules in planar cell polarity. Curr Opin Cell Biol 17: 482-488.

Shaw RM, Fay AJ, Puthenveedu MA, von Zastrow M, Jan YN, Jan LY. 2007. Microtubule plus-end-tracking proteins target gap junctions directly from the cell interior to adherens junctions. Cell 128: 547-560.

Shibamoto S, Hayakawa M, Takeuchi K, Hori T, Miyazawa K, Kitamura N, Johnson KR, Wheelock MJ, Matsuyoshi N, Takeichi M, et al. 1995. Association of p120, a tyrosine kinase substrate, with E-cadherin/catenin complexes. J Cell Biol 128: 949-957.

Shimoyama Y, Tsujimoto G, Kitajima M, Natori M. 2000. Identification of three human type-II classic cadherins and frequent heterophilic interactions between different subclasses of type-II classic cadherins. Biochem J 349: 159- 167.

Stehbens SJ, Paterson AD, Crampton MS, Shewan AM, Ferguson C, Akhmanova A, Parton RG, Yap AS. 2006. Dynamic microtubules regulate the local concentration of E-cadherin at cell-cell contacts. J Cell Sci 119: $1801-1811$.

Stepniak E, Radice GL, Vasioukhin V. 2009. Adhesive and signaling functions of cadherins and catenins in vertebrate development. Cold Spring Harb Perspect Biol 1: a002949.

Strutt H, Strutt D. 2005. Long-range coordination of planar polarity in Drosophila. Bioessays 27: 1218-1227.

Suzuki A, Ishiyama C, Hashiba K, Shimizu M, Ebnet K, Ohno S. 2002. aPKC kinase activity is required for the asymmetric differentiation of the premature junctional complex during epithelial cell polarization. J Cell Sci 115: 3565-3573.

Tachibana K, Nakanishi H, Mandai K, Ozaki K, Ikeda W, Yamamoto Y, Nagafuchi A, Tsukita S, Takai Y. 2000. Two cell adhesion molecules, nectin and cadherin, interact through their cytoplasmic domain-associated proteins. J Cell Biol 150: 1161-1176.

Takahashi K, Nakanishi H, Miyahara M, Mandai K, Satoh K, Satoh A, Nishioka H, Aoki J, Nomoto A, Mizoguchi A, Takai Y. 1999. Nectin/PRR: An immunoglobulin-like cell adhesion molecule recruited to cadherin-based adherens junctions through interaction with Afadin, a PDZ domain-containing protein. J Cell Biol 145: 539-549.

Takai Y, Irie K, Shimizu K, Sakisaka T, Ikeda W. 2003. Nectins and nectin-like molecules: Roles in cell adhesion, migration, and polarization. Cancer Sci 94: 655-667.

Takeichi M. 1988. The cadherins: Cell-cell adhesion molecules controlling animal morphogenesis. Development 102: 639-655.

Takeichi M. 2007. The cadherin superfamily in neuronal connections and interactions. Nat Rev Neurosci 8: 11-20.

Takeichi S, Otsuka H, Kimura S. 1977. Studies on tumors produced by cells transformed with herpes simplex virus type 2. Gann 68: 653-661.

Tanoue T, Takeichi M. 2005. New insights into Fat cadherins. J Cell Sci 118: 2347-2353.

Togashi H, Miyoshi J, Honda T, Sakisaka T, Takai Y, Takeichi M. 2006. Interneurite affinity is regulated by heterophilic nectin interactions in concert with the cadherin machinery. J Cell Biol 174: 141-151.

Troyanovsky S. 2005. Cadherin dimers in cell-cell adhesion. Eur J Cell Biol 84: 225-233.

Uchida N, Honjo Y, Johnson KR, Wheelock MJ, Takeichi M. 1996. The catenin/cadherin adhesion system is localized in synaptic junctions bordering transmitter release zones. J Cell Biol 135: 767-779.

Usui T, Shima Y, Shimada Y, Hirano S, Burgess RW, Schwarz TL, Takeichi M, Uemura T. 1999. Flamingo, a seven-pass transmembrane cadherin, regulates planar cell polarity under the control of Frizzled. Cell 98: 585-595.

Vasioukhin V, Bauer C, Degenstein L, Wise B, Fuchs E. 2001. Hyperproliferation and defects in epithelial polarity upon conditional ablation of $\alpha$-catenin in skin. Cell 104: $605-617$. 


\section{Adherens Junction}

Volk T, Geiger B. 1984. A 135-kd membrane protein of intercellular adherens junctions. EMBO J 3: 2249-2260.

Wang Q, Chen XW, Margolis B. 2007. PALS1 regulates E-cadherin trafficking in mammalian epithelial cells. Mol Biol Cell 18: 874-885.

Watabe-Uchida M, Uchida N, Imamura Y, Nagafuchi A, Fujimoto K, Uemura T, Vermeulen S, van Roy $\mathrm{F}$ Adamson ED, Takeichi M. 1998. $\alpha$-Catenin-vinculin interaction functions to organize the apical junctional complex in epithelial cells. J Cell Biol 142: 847-857.

Waterman-Storer CM, Salmon WC, Salmon ED. 2000 Feedback interactions between cell-cell adherens junctions and cytoskeletal dynamics in newt lung epithelial cells. Mol Biol Cell 11: 2471-2483.

Wheeler GN, Buxton RS, Parker AE, Arnemann J, Rees DA, King IA, Magee AI. 1991. Desmosomal glycoproteins I, II and III: Novel members of the cadherin superfamily. Biochem Soc Trans 19: 1060-1064.

Yamada S, Pokutta S, Drees F, Weis WI, Nelson WJ. 2005. Deconstructing the cadherin-catenin-actin complex. Cell 123: 889-901.

Yanagisawa M, Kaverina IN, Wang A, Fujita Y, Reynolds AB, Anastasiadis PZ. 2004. A novel interaction between kinesin and p120 modulates p120 localization and function. J Biol Chem 279: 9512-9521.

Yang J, Mani SA, Donaher JL, Ramaswamy S, Itzykson RA, Come C, Savagner P, Gitelman I, Richardson A, Weinberg RA. 2004. Twist, a master regulator of morphogenesis, plays an essential role in tumor metastasis. Cell 117: 927-939.

Yasumi M, Shimizu K, Honda T, Takeuchi M, Takai Y. 2003. Role of each immunoglobulin-like loop of nectin for its cell-cell adhesion activity. Biochem Biophys Res Commun 302: 61-66.

Yeaman C, Grindstaff KK, Nelson WJ. 2004. Mechanism of recruiting Sec6/8 (exocyst) complex to the apical junctional complex during polarization of epithelial cells. I Cell Sci 117: 559-570.

Yonemura S, Itoh M, Nagafuchi A, Tsukita S. 1995. Cell-to-cell adherens junction formation and actin filament organization: Similarities and differences between non-polarized fibroblasts and polarized epithelial cells. J Cell Sci 108: 127-142.

Yoshida C, Takeichi M. 1982. Teratocarcinoma cell adhesion Identification of a cell-surface protein involved in calcium-dependent cell aggregation. Cell 28: 217-224.

Yoshida-Noro C, Suzuki N, Takeichi M. 1984. Molecular nature of the calcium-dependent cell-cell adhesion system in mouse teratocarcinoma and embryonic cells studied with a monoclonal antibody. Dev Biol 101: 19-27.

Zallen JA, Wieschaus E. 2004. Patterned gene expression directs bipolar planar polarity in Drosophila. Dev Cell 6: $343-355$.

Zhang Y, Sivasankar S, Nelson WJ, Chu S. 2009. Resolving cadherin interactions and binding cooperativity at the single-molecule level. Proc Natl Acad Sci 106: 109-114. 


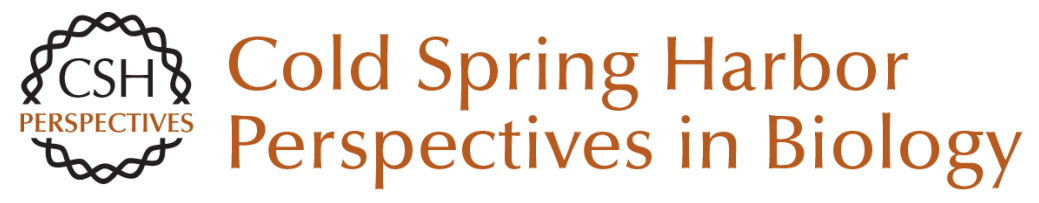

\section{Adherens Junction: Molecular Architecture and Regulation}

Wenxiang Meng and Masatoshi Takeichi

Cold Spring Harb Perspect Biol 2009; doi: 10.1101/cshperspect.a002899 originally published online August 5, 2009

\section{Subject Collection Cell-Cell Junctions}

Vascular Endothelial (VE)-Cadherin, Endothelial Adherens Junctions, and Vascular Disease Maria Grazia Lampugnani, Elisabetta Dejana and Costanza Giampietro

Adherens Junctions and Desmosomes Coordinate Mechanics and Signaling to Orchestrate Tissue Morphogenesis and Function: An Evolutionary Perspective Matthias Rübsam, Joshua A. Broussard, Sara A. Wickström, et al.

Cell-Cell Contact and Receptor Tyrosine Kinase Signaling Christine Chiasson-MacKenzie and Andrea I. McClatchey

Hold Me, but Not Too Tight---Endothelial Cell-Cell Junctions in Angiogenesis Anna Szymborska and Holger Gerhardt

\section{Connexins and Disease} Mario Delmar, Dale W. Laird, Christian C. Naus, et al.

\section{Cell Junctions in Hippo Signaling}

Ruchan Karaman and Georg Halder

Loss of E-Cadherin-Dependent Cell-Cell Adhesion and the Development and Progression of Cancer Heather C. Bruner and Patrick W.B. Derksen
Signaling by Small GTPases at Cell-Cell Junctions: Protein Interactions Building Control and Networks Vania Braga

Making Connections: Guidance Cues and Receptors at Nonneural Cell-Cell Junctions Ian V. Beamish, Lindsay Hinck and Timothy E. Kennedy

The Cadherin Superfamily in Neural Circuit Assembly James $D$. Jontes

Mechanosensing and Mechanotransduction at Cell-Cell Junctions Alpha S. Yap, Kinga Duszyc and Virgile Viasnoff

Beyond Cell-Cell Adhesion: Sensational

Cadherins for Hearing and Balance Avinash Jaiganesh, Yoshie Narui, Raul Araya-Secchi, et al.

Cell-Cell Junctions Organize Structural and Signaling Networks Miguel A. Garcia, W. James Nelson and Natalie Chavez

Cell Biology of Tight Junction Barrier Regulation and Mucosal Disease Aaron Buckley and Jerrold R. Turner

For additional articles in this collection, see http://cshperspectives.cshlp.org/cgi/collection/

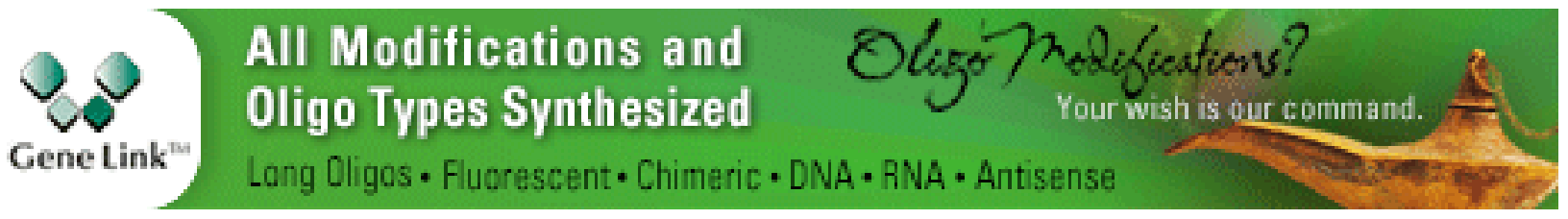


Desmosomes and Intermediate Filaments: Their Consequences for Tissue Mechanics Mechthild Hatzfeld, René Keil and Thomas $M$. Magin
Integration of Cadherin Adhesion and

Cytoskeleton at Adherens Junctions

René Marc Mège and Noboru Ishiyama

For additional articles in this collection, see http://cshperspectives.cshlp.org/cgi/collection/

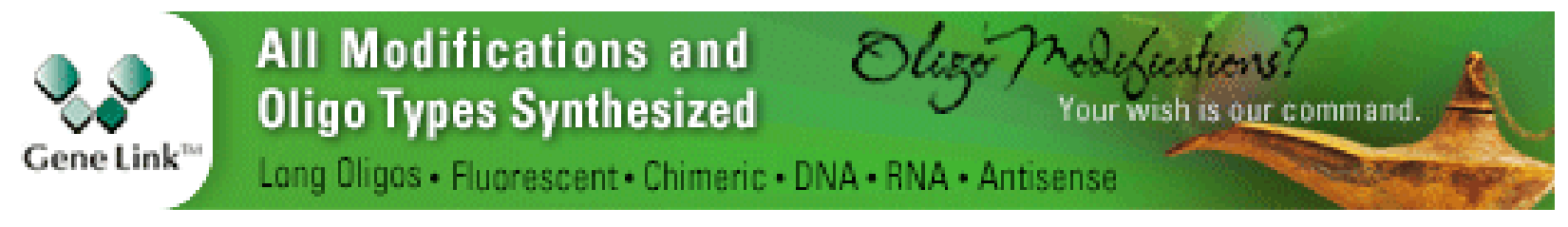

Copyright @ 2009 Cold Spring Harbor Laboratory Press; all rights reserved 